risk factor for incident gonorrhoea/chlamydia) differed in their associations with the two study outcomes. We found evidence that incident BV preceded the acquisition of gonorrhoea/chlamydia (adjusted pairwise OR [aPOR]: 1.6; 95\% CI 1.1 to 2.3), and gonorrhoea/chlamydia appeared to precede the acquisition of BV (aPOR: 2.4; $95 \%$ CI 1.7 to 3.5 ).

Conclusions Study findings provide support for the interpretation that BV is sexually transmitted. We found temporal relationships between BV and gonorrhoea/chlamydia in both directions, which suggests that treating one condition might confer protection against the other. However, this effect needs to be demonstrated in future clinical studies.

\section{P1-S5.30 RELATIONSHIP BETWEEN SYPHILIS AND HIV: LESSONS FROM A NIGERIAN SURVEILLANCE SURVEY}

doi:10.1136/sextrans-2011-050108.208

${ }^{1} \mathrm{~A}$ Adeyemi, ${ }^{1} \mathrm{~K}$ Oyediran, ${ }^{2} \mathrm{~A}$ Azeez, ${ }^{2} \mathrm{~K}$ Kawu, ${ }^{3} \mathrm{O}$ Fakunle. ${ }^{1}$ MEASURE Evaluation, Asokoro, Nigeria; ${ }^{2}$ Federal Ministry of Health, Abuja, Nigeria; ${ }^{3}$ University College Hospital, Ibadan, Nigeria

Background Sexually transmitted infections (STI) including syphilis are associated with risks of acquiring HIV infection. Behaviours that increase STI also play important role in increasing the risk of HIV. Transport workers are highly mobile population often predisposed to STI including HIV due to the nature of their business. Similarly, they are potential bridge population between female sex workers and the general population. This study assesses relationship between syphilis and HIV among transport workers in Nigeria.

Methods Secondary data analysis of a survey conducted in 2007 among 2233 transport workers in six Nigerian states. Time location sampling was employed. The relationship between HIV and syphilis was evaluated using multivariate logistic regressions while controlling for confounding factors such as demographic, knowledge and behavioural variables.

Results Median age was 33 years with age range: $18-49$ years and all participants were male. Syphilis prevalence among transport workers was $1.6 \%$. State-level prevalence of syphilis was: $4.2 \%$ in Anambra, $1.1 \%$ in Cross Rivers, $0.7 \%$ in Edo state, $1.8 \%$ in FCT, $0.8 \%$ in Kano and $1.9 \%$ in Lagos. HIV prevalence was 3.8\% with the highest prevalence $(6 \%)$ in Cross Rivers and the lowest $(1.6 \%)$ in Kano. Also, 33.5\% had genital discharge; $14.5 \%$ had genital ulcers/sores; $12.2 \%$ used marijuana; $25.0 \%$ were away from home for $>1$ month; $55.5 \%$ had secondary education and $67.2 \%$ had ever been married. Only $17.3 \%$ used condom in the last sex with non-regular partner; $31.0 \%$ had sex with a girlfriend in the past 12 months and $4.3 \%$ paid for sex in the last 12 months. Syphilis was not associated with HIV infection OR $=1.5495 \%$ CI 0.90 to 2.65. However, risks for HIV infection included being away from home for $>1$ month $\mathrm{OR}=1.895 \%$ CI 1.4 to 2.3 ; sex without condom in the last 12 months $\mathrm{OR}=1.595 \% \mathrm{CI} 1.2$ to 1.9 ; sex with female sex workers OR 1.7 95\% CI 1.2 to 2.2 while secondary education was protective with OR: $0.695 \% \mathrm{CI}$ 0.4 to 0.8 .

Conclusions More researches are needed to investigate the relationship between syphilis and HIV in Nigeria as little evidence is available from the national survey. These findings have implication of promoting secondary education and condom uptake in non-marital relationships among transport workers in Nigeria.

\section{P1-S5.31 COINFECTION AND CONCURRENT SEXUALLY TRANSMITTED INFECTIONS (STIS) IN SEXUAL PARTNERSHIPS: POTENTIAL IMPACT OF PARTNER NOTIFICATION AND TREATMENT IN STD CONTROL}

doi:10.1136/sextrans-2011-050108.209

${ }^{1} \mathrm{~F}$ Canchihuaman, ${ }^{2} \mathrm{~S}$ Hawes, ${ }^{2} \mathrm{~K}$ Holmes, ${ }^{1} \mathrm{P}$ Garcia, ${ }^{1} \mathrm{C}$ Carcamo. ${ }^{1}$ UPCH, Lima, Peru; ${ }^{2}$ University of Washington, Seattle, USA

Background Partner notification and treatment has the potential to be one of the most important strategies in the control of STIs. However, studies indicate that this approach is not often used. Additionally, there is not much information about STIs among sexual partnerships.

Objectives To determine the prevalence of several STIs in sexual partnerships and to estimate the potential utility of partner treatment. Methods We enrolled males and females 18-29 years of age from a random household sample in 24 cities in Peru and enrolled sameresidence sex partners of the participants. Participants and partners responded to demographic and sexual behaviour questionnaires and provided biological samples tested for Neisseria gonorrhoeae, Chlamydia trachomatis, and Trichomonas vaginalis, syphilis, HSV-2 and HIV.

Results Of 2302 couples enrolled, 2163 couples had laboratory results available for either CT or TV and 1696 couples for either HIV, HSV-2 or early syphilis. CT, TV, early syphilis, HSV-2, and HIV were found in $7.1 \%, 4.4 \%, 1.2 \%, 24.8 \%$, and $0.2 \%$ of couples, respectively. Among couples in which at least one subject was affected by a specific STIs, both partners had CT in 53 (39.3\%) couples, TV in 22 $(25.0 \%)$ couples, early syphilis in $3(14.3 \%)$ couples, HSV-2 in 215 (51.1\%) couples, and HIV in 2 (66.7\%). Of couples affected by CT, 18/131(13.7\%) had TV; 1/109 (1.3\%) had early syphilis; 41/109 (41.6\%) had HSV-2; and no one had HIV. Among females affected only by CT, $52.3 \%$ of partners had CT and $2.6 \%$ had TV; and among those only affected by TV, $13.7 \%$ of partners had CT and $26.2 \%$ had TV. Among males affected only by CT, $68.8 \%$ of partners had CT and $14.3 \%$ had TV; and among those affected only by TV, $11.5 \%$ of partners had CT and $84.6 \%$ had TV.

Conclusions A relatively high proportion of males and females affected by an STI had the same infection than their partners and not an infrequent number had different infections. Strategies to increase utilisation of partner notification and treatment may help STI control. Further review of partner treatment guidelines needs to be performed.

\section{P1-S5.32 THE DIFFERENTIAL ASSOCIATIONS OF HPV PREVALENCE WITH OTHER SEXUALLY TRANSMITTED INFECTIONS IN HORMONAL AND NON-HORMONAL CONTRACEPTIVE USERS}

doi:10.1136/sextrans-2011-050108.210

${ }^{1} \mathrm{~T}$ R Soong, ${ }^{1} \mathrm{P}$ E Gravitt, ${ }^{2} \mathrm{~S}$ B Gupta, ${ }^{2} \mathrm{~K}$ Liaw, ${ }^{2} \mathrm{~A}$ Tadesse, ${ }^{3} \mathrm{C}$ Phongnarisorn, ${ }^{4} \mathrm{~V}$ Wootipoom, ${ }^{5} \mathrm{P}$ Yuenyao, ${ }^{1} \mathrm{D} D$ Celentano. ${ }^{1} J o h n s$ Hopkins Bloomberg School of Public Health, Baltimore, USA; ${ }^{2}$ Merck \& Co. Inc, USA; ${ }^{3}$ Chiang Mai University, Thailand; ${ }^{4}$ Prince of Songkla University, Thailand; ${ }^{5}$ Khon Kaen University, Khon Kaen, Thailand

Background This study evaluated the associations of recent sexually transmitted infections (STIs) with cervical HPV prevalence among hormonal and non-hormonal contraceptive users.

Methods Data came from a prospective study conducted in 1046 women aged 20-38 years with normal cervical cytology in 
Thailand. We assessed whether baseline HPV prevalence was predicted by STIs which were newly detected and laboratoryconfirmed within 2 years prior to enrolment. Prevalence ratios (PRs) with 95\% CIs were estimated using generalised linear models.

Results Baseline prevalence of any HPV and high-risk (HR)-HPV were $19.9 \%$ and $8.7 \%$ respectively. Having genital chlamydia (CT) or gonorrhoea (NG) in the past 2 years was associated with increased risk of any HPV as well as HR-HPV infection after controlling for current and past sexual behaviours, age, contraceptive use and other concurrent STIs [adjusted PRs (aPRs) for any HPV: CT: 1.7 (95\% CI 1.1 to 2.7 ), NG: 1.8 (95\% CI 1.1 to 3.1); aPRs for HR-HPV: CT: 2.9 (95\% CI 1.3 to 6.5$)$; NG: 3.4 (95\% CI 1.7 to 6.7)]. Association between CT and prevalent HR-HPV was statistically significant only among non-hormonal contraceptive users [aPR: 2.7 (95\% CI 1.2 to 6.3)] but not among those using hormonal contraceptives in the past 2 years [aPR: combined oral contraceptive (COC) users: 1.1 (95\% CI 0.5 to 2.4 ); users of depot medroxyprogesterone acetate (DMPA): 1.1 (95\% CI 0.4 to 3.3)] (Abstract P1-S5.32 table 1). Association of NG with prevalent HR-HPV was observed among those who used COC [aPR: 6.2 (95\% CI 2.2 to 17.7)] or DMPA [aPR: 3.5 (95\% CI 1.1 to 10.9)] during the past 2 years but not among nonhormonal contraceptive users [aPR: 1.9 (95\% CI 0.3 to 10.3)] (Abstract P1-S5.32 table 1). No significant association was found between other STIs and baseline prevalence of HR-HPV in this cohort. Conclusions The differential impact of recent hormonal contraceptive use on the associations of CT and NG with HR-HPV prevalence suggests that the observed correlations may be attributed to biologic interactions between the pathologies of HPV and CT or NG, and not merely residual confounding by shared sexual risks.

\section{Epidemiology poster session 5: Transmission dynamic: partners: concurrency P1-S5.33 TIMING OF INCIDENT STI RELATIVE TO SEX PARTNER CHANGE IN YOUNG WOMEN}

doi:10.1136/sextrans-2011-050108.211

M Ott, J Harezlak, S Ofner, J D Fortenberry. School of Medicine, Indiana University, Indianapolis, USA

Objectives Partner concurrency is associated with STI acquisition, even when partners are sequential (ie, serial monogamy). However, little is known about the timing of STI relative to partner change. This is due, in part, to lack of documentation of STI before and after partner change. Using prospective behavioural and STI screening data, we compared the proportion of an STI occurring before and after partner change within a 12 -week period.

Methods As part of a larger study of risk and protective factors for STI in a mid-sized US city, young women provided weekly vaginal swabs and completed daily diaries of sexual behaviours for a 12week period twice a year for up to 8 years. Vaginal swabs were tested for chlamydia (CT), gonorrhoea (NG) and trichomonas (TV) using amplified DNA-based tests. We limited analysis to the 12week periods in which young women reported one sex partner change (ie, 2 sequential partners, no overlap). STIs with partner 1 were defined as those diagnosed before 1st sex with partner 2; STIs with partner 2 occurred after 1 st sex with partner 2. Published data shows a higher odds of infection after a partner change (compared to

Abstract P1-S5.32 Table 1 Association between recent genital infections and prevalent detection of high-risk HPV (N=1046)

\begin{tabular}{|c|c|c|c|c|c|c|c|c|c|c|}
\hline & \multirow{2}{*}{\multicolumn{4}{|c|}{$\begin{array}{l}\text { Total study population a } \\
\text { Detection of any HR-HPV }\end{array}$}} & \multicolumn{6}{|c|}{ Study population stratified by use of contraceptives in the past 2 years ${ }^{*}$} \\
\hline & & & & & \multicolumn{6}{|c|}{ Detection of any HR-HPV } \\
\hline & \multirow[b]{2}{*}{$\begin{array}{l}N=1046 \\
N(\operatorname{col} \%)\end{array}$} & \multirow{2}{*}{$\begin{array}{l}\text { HR-HPV+ } \\
n=91(8.7 \%) \\
\text { n (row } \%)\end{array}$} & \multirow[b]{2}{*}{ PR (95\% CI) } & \multirow[b]{2}{*}{$\mathrm{aPR}^{\neq}(95 \% \mathrm{Cl})$} & \multicolumn{2}{|c|}{$\begin{array}{l}\text { Non-hormonal contraceptive } \\
\text { users }(\mathrm{n}=339)\end{array}$} & \multicolumn{2}{|l|}{$\begin{array}{l}\text { COC users } \\
(\mathrm{n}=294)\end{array}$} & \multicolumn{2}{|l|}{$\begin{array}{l}\text { DMPA users } \\
(\mathrm{n}=413)\end{array}$} \\
\hline & & & & & PR (95\% CI) & $\mathrm{aPR}^{\S}(95 \% \mathrm{CI})$ & PR (95\% CI) & $\mathrm{aPR}^{\S}(95 \% \mathrm{Cl})$ & PR (95\% CI) & $\operatorname{aPR}^{\S}(95 \% \mathrm{Cl})$ \\
\hline \multicolumn{11}{|c|}{ Detection of the following in the past 2 years $^{\dagger}$} \\
\hline \multicolumn{11}{|c|}{ Genital chlamydia } \\
\hline No & $925(88.4)$ & $72(7.8)$ & 1 & 1 & 1 & 1 & 1 & 1 & 1 & 1 \\
\hline Yes & $121(11.6)$ & $19(15.7)$ & $\begin{array}{l}2.02(1.26 \text { to } \\
3.22)\end{array}$ & $\begin{array}{l}2.93(1.33 \text { to } \\
6.47)\end{array}$ & $\begin{array}{l}3.73(1.69 \text { to } \\
8.26)\end{array}$ & $\begin{array}{l}2.74(1.18 \text { to } \\
6.34)\end{array}$ & $\begin{array}{l}1.70(0.84 \text { to } \\
3.47)\end{array}$ & $\begin{array}{l}1.14(0.54 \text { to } \\
2.39)\end{array}$ & $\begin{array}{l}1.22(0.44 \text { to } \\
3.35)\end{array}$ & $\begin{array}{l}1.08(0.35 \text { to } \\
3.28)\end{array}$ \\
\hline \multicolumn{11}{|c|}{ Genital gonorrhea } \\
\hline No & $1020(97.5)$ & $84(8.2)$ & 1 & 1 & 1 & 1 & 1 & 1 & 1 & 1 \\
\hline Yes & $26(2.5)$ & $7(26.9)$ & $\begin{array}{l}3.27(1.68 \text { to } \\
6.36)\end{array}$ & $\begin{array}{l}3.40(1.73 \text { to } \\
6.65)\end{array}$ & $\begin{array}{l}2.31(0.37 \text { to } \\
14.46)\end{array}$ & $\begin{array}{l}1.87(0.34 \text { to } \\
10.29)\end{array}$ & $\begin{array}{l}4.24(1.79 \text { to } \\
10.03)\end{array}$ & $\begin{array}{l}6.22(2.18 \text { to } \\
17.73)\end{array}$ & $\begin{array}{l}3.29(1.13 \text { to } \\
9.60)\end{array}$ & $\begin{array}{l}3.51(1.13 \text { to } \\
10.93)\end{array}$ \\
\hline \multicolumn{11}{|c|}{ Bacterial vaginosis } \\
\hline No & $875(83.7)$ & $74(8.5)$ & 1 & 1 & 1 & 1 & 1 & 1 & 1 & 1 \\
\hline Yes & $171(16.4)$ & $17(9.9)$ & $\begin{array}{l}1.18(0.71 \text { to } \\
1.94)\end{array}$ & $\begin{array}{l}1.05(0.63 \text { to } \\
1.75)\end{array}$ & $\begin{array}{l}1.03(0.40 \text { to } \\
2.66)\end{array}$ & $\begin{array}{l}0.75(0.31 \text { to } \\
1.82)\end{array}$ & $\begin{array}{l}1.04(0.46 \text { to } \\
2.36)\end{array}$ & $\begin{array}{l}0.90(0.40 \text { to } \\
2.03)\end{array}$ & $\begin{array}{l}1.57(0.66 \text { to } \\
3.68)\end{array}$ & $\begin{array}{l}1.46(0.57 \text { to } \\
3.70)\end{array}$ \\
\hline \multicolumn{11}{|c|}{ Positive for HSV-2 serology } \\
\hline No & $626(59.9)$ & $47(7.5)$ & 1 & 1 & 1 & 1 & 1 & 1 & 1 & 1 \\
\hline Yes & $420(40.2)$ & $44(10.5)$ & $\begin{array}{l}1.40(0.94 \text { to } \\
2.07)\end{array}$ & $\begin{array}{l}1.26(0.83 \text { to } \\
1.91)\end{array}$ & $\begin{array}{l}1.99(0.90 \text { to } \\
4.38)\end{array}$ & $\begin{array}{l}1.75(0.78 \text { to } \\
3.90)\end{array}$ & $\begin{array}{l}1.53(0.84 \text { to } \\
2.80)\end{array}$ & $\begin{array}{l}1.67 \text { (0.89 to } \\
3.15)\end{array}$ & $\begin{array}{l}0.88(0.41 \text { to } \\
1.88)\end{array}$ & $\begin{array}{l}0.73(0.30 \text { to } \\
1.79)\end{array}$ \\
\hline
\end{tabular}

The following covariates were not found to be statistically significantly associated with the outcomes $(\mathrm{P}>0.05)$ and did not significantly influence the effect size of the primary association of interest $(<10 \%)$, and hence were not included in the final models: parity, smoking status, as well as other parameters assessed for sexual behavior, including age of sexual debut, having new partner in the past year, number of sex partners in the past year, frequency of sex in last 6 months.

HR-HPV: High-risk HPV, defined as HPV types 16, 18, 31, 33, 35, 39, 45, 51, 52, 56, 58, 59, 66 (IARC 2007).

* Subjects were formerly enrolled in a 2-year study addressing the effects of hormonal contraceptive use on HIV acquisition (HC-HIV). These subjects were required to adhere to the selfselected contraceptive method for at least 1 year of follow-up in that study (Morrisonet al. AIDS. 2010;24:1778-81). These subjects were reconsented at the end of that study for inclusion in the current study.

† Genital infections were detected in pelvic exams and confirmed by laboratory assays.

‡ Estimates adjusted for age at baseline of the current study, number of lifetime partners, partners having sex with others in last 6 months, male partner using condom in last 6 months, other concurrent genital infections, types of contraceptive use in the past 2 years.

$\S$ Estimates adjusted for age at enrollment of the current study, number of lifetime partners, partners having sex with others in last 6 months, male partner using condom in last 6 months, other concurrent genital infections.

COC, combined oral contraceptives; DMPA, depot medroxyprogesterone acetate; HSV-2, Herpes simplex virus 2; PR, Prevalence ratio. 